\title{
Development of Conventional Controller Based on Image Processing for Monitoring and Controlling Burning Zone Temperature in a Cement Plant in Rotary Kiln Process Through IOT
}

\author{
Polaiah Bojja ${ }^{1 *}$, N. Merrin Prasanna ${ }^{2}$, Pamula Raja Kumari ${ }^{3}$, T. Bhuvanendhiran ${ }^{4}$, Panuganti Jayanth Kumar ${ }^{1}$ \\ ${ }^{1}$ Department of ECE, Koneru Lakshmaiah Education Foundation, K L E F Demeed to be University, Green Fields, \\ Vaddeswaram, Guntur 522502, Andhra Pradesh, India \\ ${ }^{2}$ Sri Venkateswara Institute of Science and Technology (SVIST), Y.S.R. Kadapa 516003, Andhra Pradesh, India \\ ${ }^{3}$ Department of Mathematics, Koneru Lakshmaiah Education Foundation, K L E F Demeed to be University, Green Fields, \\ Vaddeswaram, Guntur 522502, Andhra Pradesh, India \\ ${ }^{4}$ Department of ECE., T. Thimmaiah Institute of Technology, kgf. Karnataka 563113, India
}

Corresponding Author Email: paulraj.bojja@gmail.com

https://doi.org/10.18280/i2m.200405

Received: 31 December 2020

Accepted: 29 April 2021

\section{Keywords:}

burning zone, flame image, temperature, PID

controller, pixel or shading

\begin{abstract}
In the cement factories, a rotary kiln is a pyro-processing device that is used to raise the temperature of the materials in a continuous process. Temperature monitoring is an essential process in the rotary kiln to yield high quality clinker and it has been implemented using various image processing techniques. In this paper we are measuring and controlling the temperature of rotational kiln in cement industry to get proper clinker ouput. Burning zone flame images are captured using $\operatorname{CCD}$ (Charge Coupled Device) camera and are processed using image processing with PID(Proportion Integration and Derivative) controller and which are programmed on raspberry pi card with the help of python language, also the captured images and attributes are transferred to authorized mobile/pc through Raspberry PI by selecting the IP address of mobile or PC. All the attributes received in the mobile in the form of web page the according to the object following data temperature controlled and object is ceaselessly followed to get the proper clinker output. Picture handling calculation with Open cv, as indicated by the calculation the edge estimation of the camera is settled. The frame value of the camera is set. Conversion from RGB color space to HSV color space is achieved and the reference color threshold value is determined. The range esteem estimated by the camera is contrasted and the reference esteem. In this study temp of rotational kiln is measured effectively using PID controller, this controller continuously control the temperature of revolving kiln by varying the $\mathrm{i} / \mathrm{p}$ images of burning zone at finally fix one flame which is giving 1400degc.
\end{abstract}

\section{INTRODUCTION}

Today, individuals' security demands are continually and mechanized robotization frameworks quality and quick reaction, considering his place in his life the plan of mechanical frameworks has gotten key. Article following, particularly at cement packing, Auto temperature finding in revolving kiln and item following focuses recognition in robot applications and curve welding robots at a steady speed of focuses and articles that should be development and change speed unpredictably. The cycle is getting more diligently. Open-close with sensor approach thus a more minimized route as opposed to framing an administrative body PID of the item wanted to be distinguished by picture handling It is more delicate to catch up with the review body and It produces dependable outcomes [1-3]. PID regulator examines were first begun in the naval force in 1922.Minorsky for programmed directing frameworks on ships It was applied by Minorsky [4]. PID controller studies were first started in the navy in 1922. With the simple structure of PID most of the industries adapting. Due to its simple structure of PID, it is widely used in different fields. Temperature detection with image processing, different studies have been done and these are applied in various fields to control speed, stability, error. It has formed its usage fields in the industry, in this method PID based image processing is used to measures the temperature using burning flame image in which it is considered Red, Green, Blue (RGB) magnitude planes. The system takes RGB magnitude as input variable and generates temperature as output. The proposed PID controller detects temperature of flame zones using color features of burning flame images, precise temperature mapping of flame images helps to control the temperature inside the rotational kiln to produce high quality clinker. This process can be viewed remotely and controlled using various control loops from anywhere.

\section{RASPBERRY PI MODEL B}

Raspberry Pi, ARM1176JZF-S $700 \mathrm{MHz}$ CPU on Broadcom BCM2835 central processor, for this board it is having all features like processor, memory, input-output units. Broadcom BCM2835 - 700 Mhz ARM1176JZF-S, 512MBRam, USB 2.0, HDMI space, SD card per user, $3.5 \mathrm{~mm}$ 
sound jack, RCA video yield, CSI association, 10/100 Ethernet, Camera port.

\section{OPENCV LIBRARY}

OpenCV, created by the Intel firm Berkeley It is an open source programming authorized by Software Distribution (BSD). It is the library. Various PC vision calculations including. OpenCV library, $\mathrm{C}$ and $\mathrm{C}++$ by Intel created in programming dialects. Macintosh, Windows, Linux and so forth. It can chip away at stages [5]. Object investigation, military applications, security frameworks, clinical picture preparing applications, satellite Often OpenCV in picture and guide applications library is utilized. OpenCV form 2.3.1 is utilized in this examination. what's more, from its source code on the Raspberry Pi advancement board It has been ordered. Again, the use of OpenCV library in this study to Set the color values of the object to be detected as a threshold [5-11].

\section{A. Pre-processing}

The ideal examination of dependability is expanded by picture preprocessing systems. Typically every picture contains low recurrence commotion, so to seize undesirable data (clamor) picture needs to go through preprocessing stage [12]. The preprocessing is needed to improve the subtleties in picture. The picture upgrade changes the visual effect of the picture and improves the picture quality. In this work the upgrade is conveyed by middle channel.

\section{B. Median Filtering}

It is a nonlinear filter which preserves the edges of an image by confiscating the low frequency noise [13]. The random noise within communication channel generates a salt and pepper noise. It is a simple sliding spatial window that substitutes the middle value with average value of all pixels in the window. The window is usually a square kernel. The operation of filter is defined by the Eq. (1)

$$
\text { median }[\mathrm{M}(\mathrm{s})]+\text { median }[\mathrm{N}(\mathrm{s})]
$$

The signal processing procedure is able to perform the noise reduction in an image to get good perception. The objective of this filter is to sprint the image with pixel by pixel and replacing the each and every neighboring pixel with its median value. The configuration of neighbors is known as "window" which slithers pixel by pixel in entire image.

\section{Segmentation}

Region of picture into its constituent areas is known as division. It just changes the picture portrayal. Also, it is ordinarily used to limit articles and boondocks in pictures [14]. Ordinarily it is performed with various methods, for example, thresholding [6], Region based or locale developing and some other wavelet changes. Yet, all the division methods don't fragment the influenced part precisely. So in this work to identify or section the influenced part the cuckoo inquiry advancement method alongside thresholding is utilized as division apparatus.

\section{Feature extraction}

Highlight extraction is where it creates a lot of highlights otherwise called vectors. It depicts the substance of the picture and establishes the portrayal of the given picture. The capacity of Local Binary Pattern highlight extraction is to blackmail the highlights of relating area of worry in a picture.

\section{E. Classification}

This refers to carrying out data classes from a raster image with multiple bands. For creating topical maps the following raster from the image classification may be used. There are two types of classifications which depend on the cooperation between the expert and the PC in classification, namely supervised and Unsupervised. In this work $\mathrm{CNN}$ is used as classifier.

\section{F. Feature extraction}

Feature extraction is a process where it generates a set of features also known as vectors. It describes the contents of the image and constitutes the representation of the given image. The function of Local Binary Pattern feature extraction is to extort the features of corresponding region of concern in an image

\section{TEMPERATURE DETECTION AND VALIDATING METHOD}

Of the object of enthusiasm for object recognition applications there can be many distinctive component esteems. This In the investigation, the shading property of the item was utilized. With the picture preparing procedure in the work performed discovery and following of the item in Figure 1 taken from the camera the guide given beneath has been followed for the activities:

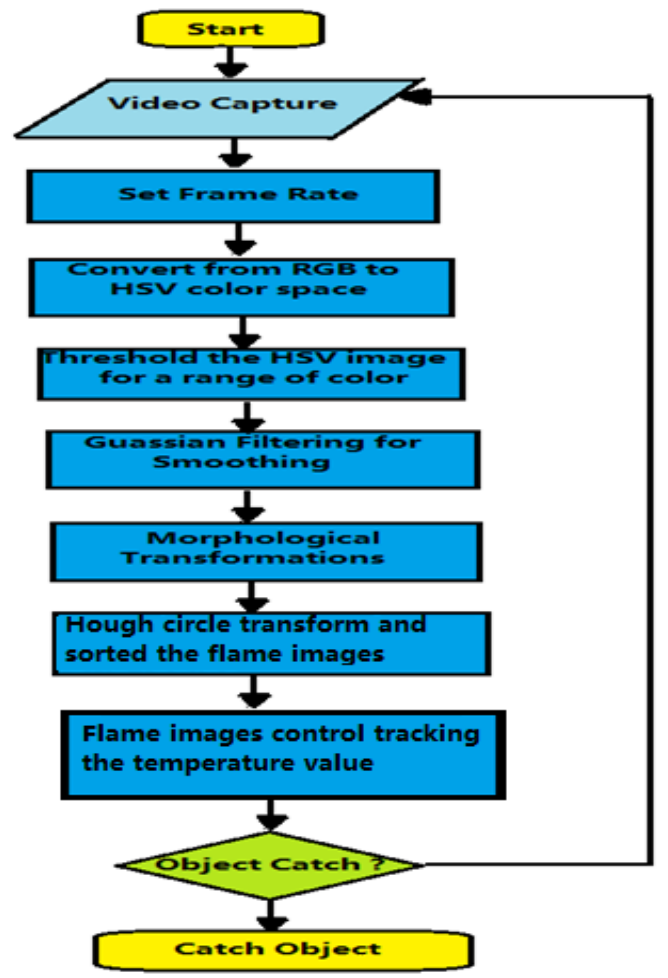

Figure 1. Image processing diagram

\section{TEMPERATURE TRACKING AND IMAGE PROCESSING}

From the caught digital frames of flame singular pixels can be isolated utilizing region developing system. Pixel area and its Red (R), Green (G) and Blue (B) colour [11] properties will be acquired for singular pixels. A color histogram can be utilized to speak to the colour arrangements of a picture.

Image processing calculation with Open CV shows up in the diagram. According to the algorithm, the frame value of the camera is setted. Conversion from RGB color space to HSV 
color space is achieved and the reference color threshold value is determined. Parasitic pictures are impeded by morphological sifting. Consuming zone pictures are recognized and their temperature is resolved (Figure 2).

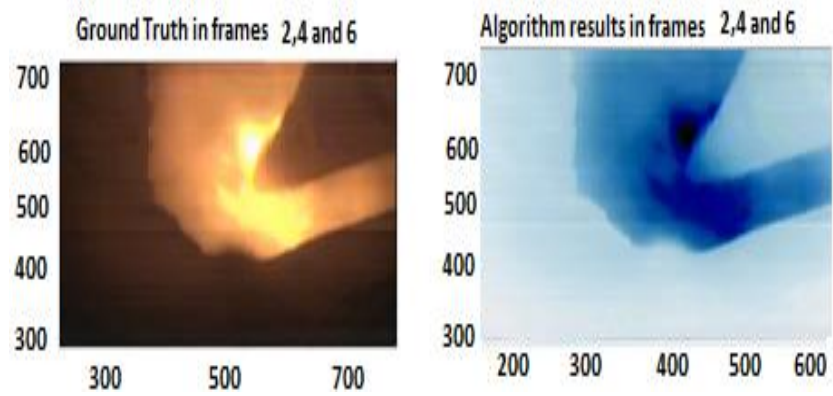

Figure 2. Burning image co-ordinates

From Table 1 different images are giving various temperature values with error. By comparing the input image with set point we can judge which image is the best for giving proper clinker output. With the help of Table 1 we can control the raw meal feed rate, coal feed rate, \% oxygen.

Table 1. Burning zone flame images with temperature and error value

\begin{tabular}{|c|c|c|}
\hline Image & $\begin{array}{c}\begin{array}{c}\text { Measured Temperature (Deg - } \\
\text { centigrade) }\end{array} \\
\end{array}$ & Error \\
\hline & 650 & 750 \\
\hline & 750 & 650 \\
\hline & 1350 & 50 \\
\hline & 920 & 480 \\
\hline & 1100 & 300 \\
\hline & 1243 & 157 \\
\hline & 1300 & 100 \\
\hline & 850 & 550 \\
\hline & 1370 & 30 \\
\hline & 1389 & 11 \\
\hline
\end{tabular}

In the catch of the article, the item sweep check is the info esteem. The pixel value which is esteem estimated by object following is contrasted and reference range. Range contrast is viewed as an error. Finding and controlling of temperature is performed by PID control as indicated by the determined error share and the directions of the article. These tasks proceed until the right image is caught to get the proper clinker ouput. In this we have taken 10 images randomly and measured the temperature and catch the right flame image to maintain constant temperature of $1400 \mathrm{deg}$ centigrade approximately to get the proper clinker output.

\section{A. PIDDC Motor Control}

PID stands for proportional, integral and derivative controls. Because of its straight forward structure, the business is broadly utilized. PID acknowledges the distinction between the desired value and the reference an incentive inside the cycle as an error. It controls the cycle contribution to limit [8] the error value. The range esteem estimated by the camera is contrasted and the reference esteem. In this examination, the temperature of the burning zone is measured more proficiently by PID control. Implementation process of image processing technique detecting and controlling of temperature is shown below (Figure 3) [15, 16].

Step 1: Catching the picture from the camera

Step 2: Making the pictures taken in outlines

Step 3: HSV from RGB space of the picture in the frame Conversion to shading space

Step 4: Taking an edge for the decided shading esteem.

Step 5: Utilization of "Smoothing" from morphological cycles.

Step 6: By applying a median channel, the chromatic clamors anticipation

Step 7: The pixels that are twofold '1' in the subsequent paired picture pixel estimation of the item by finding the focal point of gravity as decided its area.

Step 8: Drawing the way of the item whose area is determined.

Step 9: The identification purpose of the picture taken from the camera error comparative with the good ways from the middle point Determination of significant worth

Step 10: PI control of determined blunder esteem Application of the calculation to the information

Step 11: Hough image transform and sorted image position and radius

Temperature control and object tracking

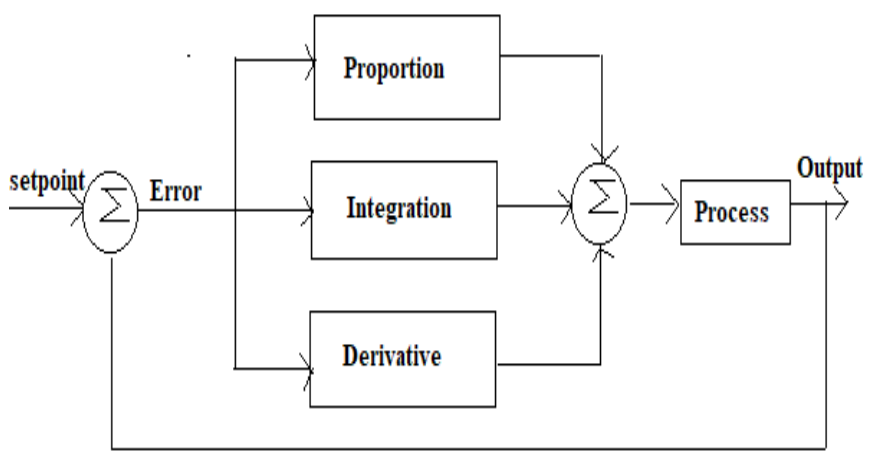

Figure 3. Temperature monitoring and controlling burning Diagram

\section{B. Result image processing pi introduction to algorithm}

Images which taken from the camera requested reference point is the pixel $\mathrm{d}$ in the middle of the camera value is image center of gravity calculated by matching $[17,18]$ and camera search for column value of middle pixel the difference as PI to be applied to the input of the controller an error value form. Feed back PI control systems in a digital environment when requested to apply PI [10] inspection discrete signal must be 
processed in time. This discrete in study time PI control signal set point $1423 \mathrm{deg}$ centigrade. At this temperature proper clinker output will be produced.

\begin{tabular}{|c|c|}
\hline 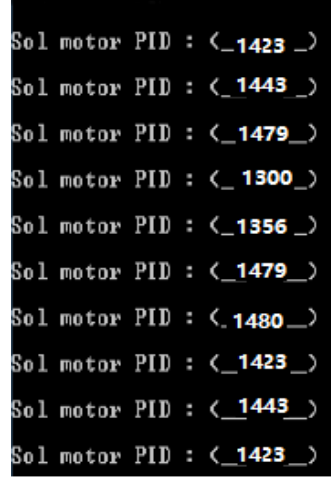 & 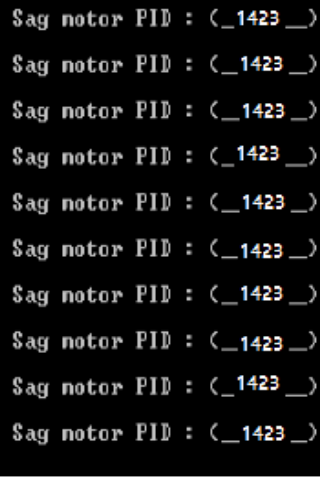 \\
\hline
\end{tabular}

Figure 4. The results of the Temperature example PID consisting of control signal

Figure 4 is an example case, followed move the subject to the right in front of the camera PI the controller will produce to fix the error the signal it emits is a section is given as an example. Here 1480 is the largest overshoot.

Example of split raise according to the man PI control signal, tracking in control mechanism of the object in front of the camera to keep the position stable $12 \mathrm{v}$ at 2000rp.Here taking 10 images at once and given the results. Results of the tracking temperature to the right of the midpoint in the camera time around taken from the slice.

Table 2. The tracked temperature of burning zone with percentage of error

\begin{tabular}{cccc}
\hline $\begin{array}{c}\text { Sample } \\
\text { order }\end{array}$ & $\begin{array}{c}\text { Temperature (Deg } \\
\text { centigrade) }\end{array}$ & $\begin{array}{c}\text { Error } \\
(\%)\end{array}$ & $\begin{array}{c}\text { Duty cycle } \\
\text { ratio }\end{array}$ \\
\hline 1 & 750 & 6.5 & $51.85 \%$ \\
2 & 650 & 7.5 & $56.25 \%$ \\
3 & 1350 & 50 & 1350 \\
4 & 920 & 4.8 & $58.98 \%$ \\
5 & 1100 & 3 & $60.35 \%$ \\
6 & 1243 & 1.5 & $72.12 \%$ \\
7 & 1300 & 1 & $85.19 \%$ \\
8 & 850 & 5.5 & $57.42 \%$ \\
9 & 1370 & 0.3 & $92.24 \%$ \\
10 & 1423 & 0.1 & $98.10 \%$ \\
\hline
\end{tabular}

From the data base for every 10 images for a second, during this time stamp different images are giving different temperature values. Actual temperature to get proper clinker was kept in set point, example set point is 1400 deg centigrade, this set point was get compared with the actual captured images.so that getting big error (Table 2).

\section{DATA TRANSFER/ACCESS THROUGH IOT}

As a newer generation of computer technology, the IoT brings a new platform to industrial engineering that connects sensors and channels to conventional control systems like temperature control thereby allowing them to be allocated knowledge and deeper contact and interaction between remote authorized person and data base administrator. In addition to the benefit of clients IoT also serves the entire rotary kiln burning zone, where a wide range of controlling devices are linked to the present cement industry burning zone, the burning zone video frames are transmitted to the remote technical center, and data base administrator is able to monitor flame images remotely and provide better temperature flame to get the proper clinker output.

In this work for sharing the information to client or remotely connecter DBA the raspberry $\mathrm{Pi}$ processor is used. The Raspberry pi is a mini computer that is built in a single board with all the essential components that can be used for many of the computer's activities, such as sports, word processing, spreadsheets, and HD video playback. It's a compact and low cost raspberry pi deck. It has a chip (SoC) Broadcom BCM2835 device including Video Core IV GPU and ARM1176JZF-S $700 \mathrm{MHz}$ core which was initially designed with 256 megabytes of RAM, later upgraded to $512 \mathrm{MB}$. It uses SD card for storage and booting even it does not contain a solid-state or an internal hard disk. The Raspberry pi does not have its own display unit, it is possible to connect HDTV displays or monitors to the raspberry pi board. The raspberry pi board is made up of one Ethernet port, four USB ports, HDMI port, and 40 GPIO pins. The raspberry Pi runs and uses the Linux operating system. The Raspberry pi board is shown in Figure 5. The hardware of Raspberry Pi has evolved through various versions with memory and device support. The A+ model is used in this work as shown in Figure 5.

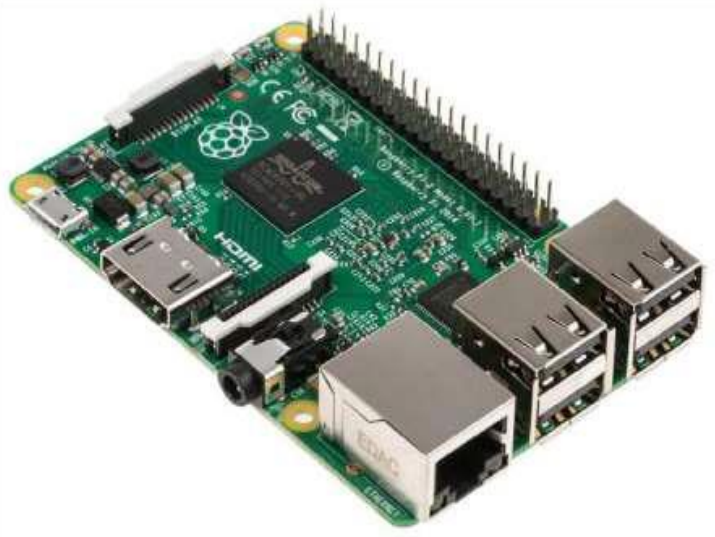

Figure 5. Raspberry Pi module

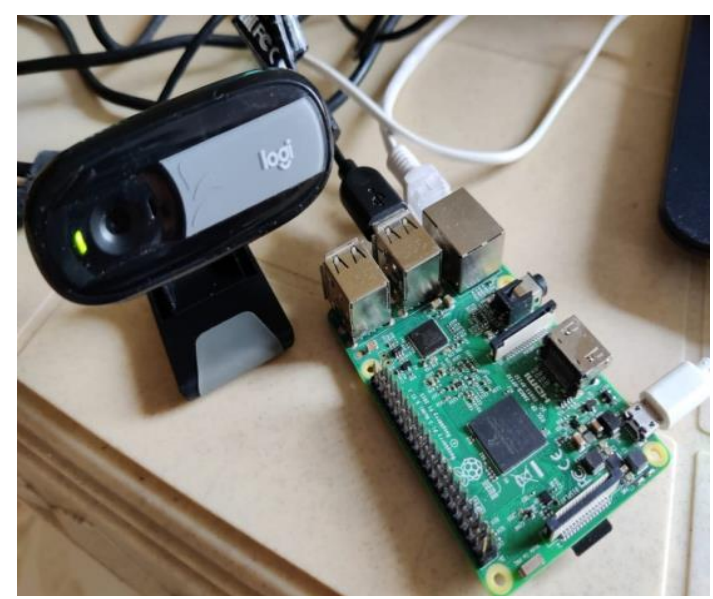

Figure 6. Hardware implementation

To Transfer the attributes obtained from the MATLAB the Raspberry processor is connected to one of the port to PC which is installed with MATLAB Program through Transmitter \& Receiver Bus. The hardware implementation is as shown in Figure 6. 
To operate with Raspberry PI separate PC is connected to the processor with HDMI cable where the information transferring program is loaded which is usually written in Php. The interface of processor and PC is shown in Figure 7.

To share the attributes obtained from the MATLAB, on GUI SEND TO IOT push button is available by clicking on that push button the attributes are transferred to authorized mobile/pc through Raspberry PI by selecting the IP address of mobile or PC. All the attributes received in the mobile in the form of web page is as shown in Figure 8.

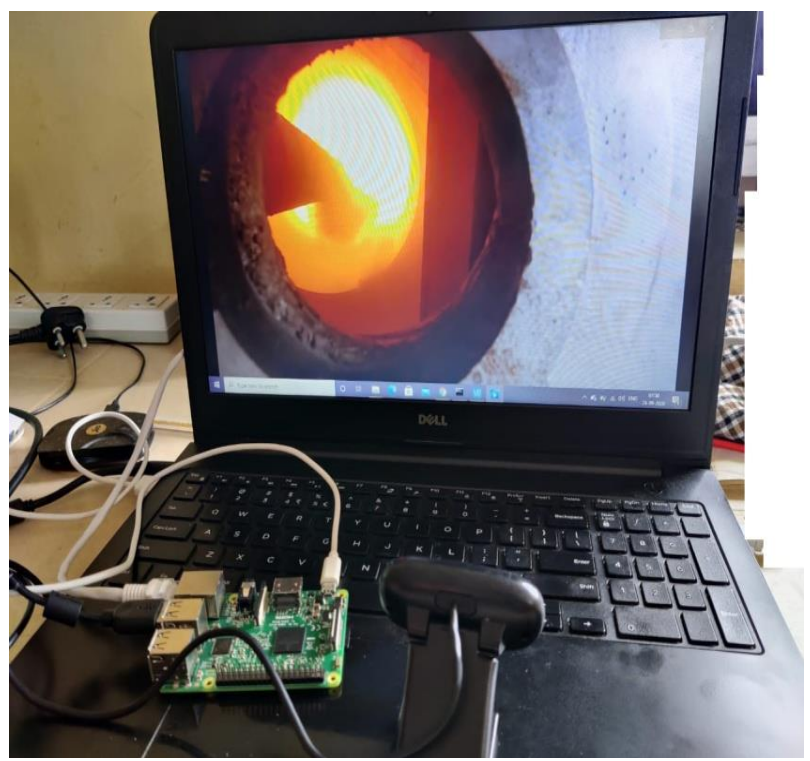

Figure 7. Interface of Raspberry PI to PC

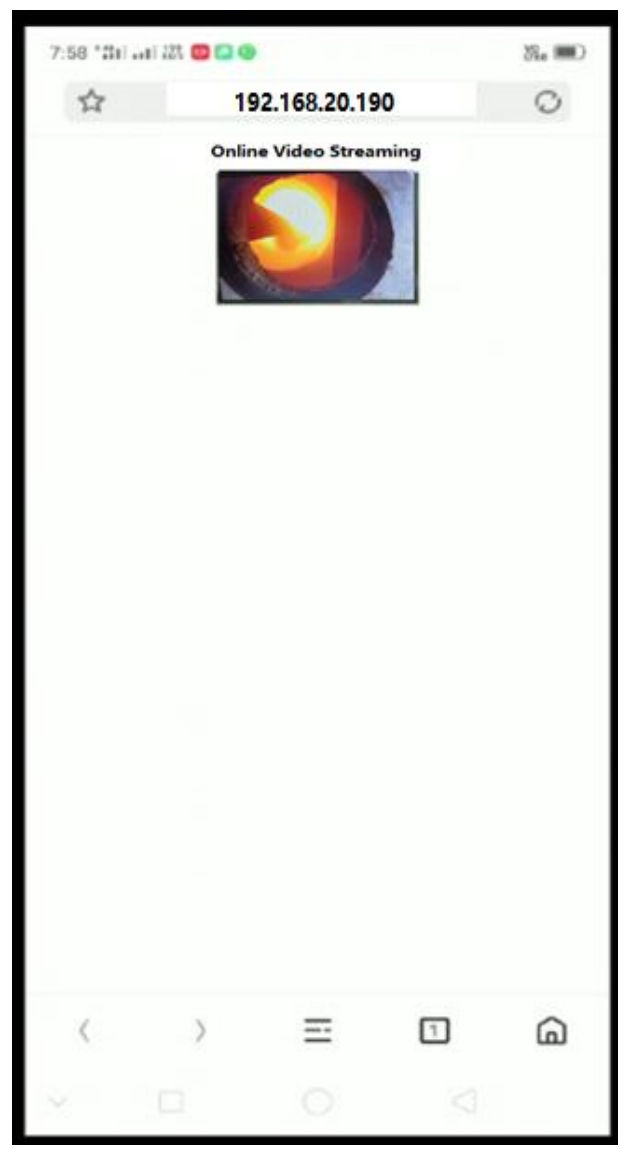

Figure 8. Attributes received to Mobile through IoT
Working of Internet based Process Control in Industries, Currently, to monitor and control the process in real time, all the industries utilize the IoT based techniques. The machines and motors all are connected by a network to share the data to the authorized persons. The centralized data sharing environments like SharePoint portal service, mobile computing, cloud computing and fog computing techniques are applied to enable remote control and to access data from anywhere. In previous days, the data communication rate was like $1 \mathrm{mbps}, 10 \mathrm{mpbs}$, and $100 \mathrm{mbps}$. The advancement in the communication technology and protocols support transmission of data in high speed rate of Gbps. At present, every $3 \mathrm{G}$ mobile have the feature of Voice over on long term evolution (VoLTE). It supports web-based applications like skype service, HD video streaming, etc. Recently, the voicebased control framework is applied in various industries. The fuzzy based system is designed in various engineering fields such as chemical, civil, mechatronics, electronics and electrical. The system designed using Arduino, Raspberry Pi and the communication techniques such as Wi-Fi, Bluetooth, Ethernet enable people to monitor and control their organization remotely and the data visualization in the form of graphs, chart provides the data patterns which is used to analyze and predict the quality of the outcome. The cement industries also utilize the internet-based environment called ediagnose Izee Diag which is used to examine the plant remotely.

\section{CONCLUSION}

This paper proposes a PID based image processing system to measure the temperature using flame images in the cement industry. Precise temperature mapping of flame images is performed to control the temperature inside the rotating kiln to produce high quality clinker. Industrial IoT PID based image processing system framework is developed in this work which uses web-based application to control the process from anywhere. Thus finally temp of rotational kiln is measured effectively using PID controller, this controller continuously control the temperature of revolving kiln by varying the $i / p$ images of burning zone at finally fix one flame which is giving 1400 degc.

\section{REFERENCES}

[1] Xu, D., Wang, L.K., Tan, M. (2004). Image processing and visual control method for arc welding robot. 2004 IEEE International Conference on Robotics and Biomimetics, Location: Shenyang, China. https://doi.org/10.1109/ROBIO.2004.1521871

[2] Bolmsjö, G., Olsson, M., Cederberg, P. (2002). Robotic arc welding - trends and developments for higher autonomy. Industrial Robot, 29(2): 98-104.

[3] Yu, J.Y., Na, S.J. (1997). A study on vision sensors for seam tracking of height - varying weldment, part 1: Mathematical model. Mechatronics, 7(7): 599-612. https://doi.org/10.1016/S0957-4158(97)00023-8

[4] Minorsky, N. (1922). Directional stability of automatically steered bodies. Journal of the American Society for Naval Engineers, 34(2): 280-309. https://doi.org/10.1111/j.1559-3584.1922.tb04958.x 
[5] Merrin Prasanna, N., Bojja, P. (2019). Optimization of rotary kiln in cement industry using conventional control systems. HELIX -the Scientific Explorer, 4843-4849. https://doi.org/10.29042/2019-4843-4849.

[6] Venkatesh, C., Bojja, P. (2019). A novel approach for lung lesion segmentation using optimization technique. HELIX the Scientific Explorer, 9(1): 4832-4837. https://doi.org/10.29042/2019-4832-4837

[7] Vasavi, C., Kumar, G.S., Murty, M.S.N. (2019). Generalized differentiability and integrability for fuzzy set-valued functions on time scales. Soft Computing, 20: 1093-1104. https://doi.org/10.1007/s00500-014-1569-1

[8] Balasubba Reddy, M., Obulesh, Y.P., Sivanagaraju, S., Suresh, C.V. (2015). Mathematical modelling and analysis of generalised interline power flow controller: an effect of converter location. Journal of Experimental \& Theoretical Artificial Intelligence, 1(9): 655-671. https://doi.org/10.1080/0952813x.2015.1042529

[9] Pradhan, A., Sekhar, K.R., Swain, G. (2018). Digital image steganography using LSB substitution, PVD, and EMD. Mathematical Problems in Engineering, 9(1). https://doi.org/10.1155/2018/1804953

[10] Thumu, R., Harinadha, R.K. (2019). Pi, fuzzy based controllers for facts device in grid connected PV system. International Journal of Integrated Engineering, 11(6): 176-185.

[11] Surekha, B., Vundavilli, P.R., Parappagoudar, M.B., Srinath, A. (2011). Design of genetic fuzzy system for forward and reverse mapping of green sand mould system. International Journal of Cast Metals Research, 4(6):

53-64. https://doi.org/10.1179/1743133610y.0000000002

[12] Kishore, P.V.V., Kumar, K.V.V., Kumar, E.K., Sastry, A.S.C.S., Kiran, M.T., Kumar, D.A., Prasad, M.V.D.
(2018). Indian classical dance action identification and classification with convolutional neural networks. Advances in Multimedia, 2018: 5141402. https://doi.org/10.1155/2018/5141402

[13] Merrin Prasanna, N, Polaiah, B. (2020). Design and real time implementation of ANFIS controller for optimizing the burning zone temperature in rotary kiln in cement industry. Journal of Research on the Lepidoptera, 51(2): 480-498. https://doi.org/10.36872/LEPI/V51I2/301113

[14] Merrin Prasanna, N., Polaiah, B. (2017). Computational intelligence survey analysis for advanced modeling and development of intelligent controller based on wireless sensor networks for industrial application. Journal of Advanced Research in Dynamic and Control Systems, 9(6): 264-280.

[15] Merrin Prasanna, N., Polaiah, B. (2020). Development of mathematical model based ROI for rotary kiln to measure burning zone temperature in cement industry by digital image processing. International Journal of Control and Automation, 13(2): 416-427.

[16] Asoke Nath, P. (2017). Detection of different stages of lungs cancer in CT - Scan images using image processing techniques. International Journal of Innovative Research in Computer and Communication Engineering, 5(5): 9708-9719.

[17] Gajdhane, V.A., Deshpande, L.M. (2014). Detection of lung cancer stages on $\mathrm{CT}$ scan images by using various image processing techniques. IOSR Journal of Computer Engineering (IOSR-JCE), 16(5).

[18] Liu, B., Fang, L.Y., Long, R., Lan, X., Chou, K.C. (2016). IEnhancer-2L: A two-layer predictor for identifying enhancers and their strength by pseudo k-tuple nucleotide composition. Bioinformatics, 32(3): 362-369. https://doi.org/10.1093/bioinformatics/btv604 